\title{
Nidificação de abelha Xylocopa spp. no seridó oriental da Paraíba, Brasil
}

\author{
Xylocopa spp. bee nesting in the eastern seridó of Paraiba, Brazil \\ Nidificación de abejas Xylocopa spp. en el seridó oriental de Paraíba, Brasil
}

Recebido: 11/06/2021 | Revisado: 22/06/2021 | Aceito: 22/06/2021 | Publicado: 05/07/2021

Francisca Tatiana de Oliveira Souza
ORCID: https://orcid.org/0000-0002-4177-2803
Instituto Federal de Educação, Ciência e Tecnologia da Paraíba, Brasil
E-mail: tatianaoliveiraifpb@gmail.com
Italo de Souza Aquino
ORCID: https://orcid.org/0000-0002-7948-8760
Universidade Federal da Paraíba, Brasil
E-mail: italo.aquino@terra.com.br
Alex da Silva Barbosa
ORCID: https://orcid.org/0000-0002-7343-6134
Universidade Federal da Paraíba, Brasil
E-mail: aldasibarbosa@cchsa.ufpb.br
Péricles de Farias Borges
ORCID: https://orcid.org/0000-0003-3585-1342
Universidade Federal da Paraíba, Brasil
E-mail: pericles@cca.ufpb.br

\begin{abstract}
Resumo
As abelhas Xylocopa spp. estão presentes nos mais diversos ecossistemas e geralmente apresentam hábito solitário. Estas abelhas constroem seus ninhos em troncos de madeira morta, seca e em estágio preliminar de decomposição e são os agentes polinizadores de maior eficiência na polinização do maracujazeiro (Passiflora edulis f. flavicarpa Deg.). O conhecimento do hábito de nidificação em seu habitat (natural) constitui-se em elemento fundamental para o uso de colmeias racionais dessas abelhas em plantios de P. edulis. Este trabalho teve como objetivo analisar o comportamento de nidificação de Xylocopa spp levando-se em consideração: orientação magnética de nidificação (pontos cardeais e colaterais), substrato utilizado, diâmetro do substrato, diâmetro do alvado e altura do ninho em relação ao solo. A pesquisa foi conduzida em propriedades localizadas no município de Picuí, microrregião do Seridó Oriental Paraibano. Realizou-se uma Análise de Variância (ANOVA) e a média comparada pelo teste de Tukey $(\mathrm{p} \leq 0,05)$. Nesta microrregião foram identificadas duas espécies de Xylocopa: X. (Neoxylocopa) grisescens Lepeletier, 1841 e X. (Neoxylocopa) cearenses Ducke, 1910). Estas espécies apresentaram hábitos de nidificação em cajueiro (Annacardium occidentale), umburana (Commiphora leptophloeos), mulungú (Erythrina mulungu) e caubeira (Tabebuia caraiba). Estas abelhas apresentam preferência de nidificação na direção voltada para o ponto colateral Sudoeste (SW).
\end{abstract}

Palavras-chave: Nidificação; Orientação magnética; Abelhas nativas.

\begin{abstract}
The Xylocopa spp. bees are present in the most diverse ecosystems and usually have a solitary habit. These bees build their nests in trunks of dead wood, dry and in a preliminary stage of decomposition and are the most efficient pollinating agents in the pollination of passion fruit (Passiflora edulis $f$. flavicarpa Deg.). The knowledge of the nesting habit in their (natural) habitat is a fundamental element for the use of rational hives of these bees in $P$. edulis plantations. This work aimed to analyze the nesting behavior of Xylocopa spp taking into account: magnetic nesting orientation (cardinal and collateral points), substrate used, substrate diameter, daylight diameter and nest height in relation to the ground. The research was conducted in properties located in the municipality of Picuí, micro-region of the Seridó Oriental Paraibano. An Analysis of Variance (ANOVA) was performed and the mean compared by Tukey's test $(\mathrm{p} \leq 0.05)$. In this microregion, two species of Xylocopa were identified: X. (Neoxylocopa) grisescens Lepeletier, 1841 and X. (Neoxylocopa) cearenses Ducke, 1910). These species showed nesting habits in cashew (Annacardium occidentale), umburana (Commiphora leptophloeos), mulungú (Erythrina mulungu) and cowberry (Tabebuia caraiba). These bees have a nesting preference towards the southwestern (SW) collateral point.
\end{abstract}

Keywords: Nesting; Magnetic orientation; Native bees.

\section{Resumen}

Las abejas Xylocopa spp. están presentes en los más diversos ecosistemas y suelen tener un hábito solitario. Estas abejas construyen sus nidos en troncos de madera muerta, secos y en una etapa preliminar de descomposición y son los agentes polinizadores más eficientes en la polinización de la maracuyá (Passiflora edulis f. flavicarpa Deg.). El conocimiento 
del hábito de anidación en su hábitat (natural) es un elemento fundamental para el uso de colmenas racionales de estas abejas en plantaciones de $P$. edulis. Este trabajo tuvo como objetivo analizar el comportamiento de anidación de Xylocopa spp teniendo en cuenta: orientación magnética de anidación (puntos cardinales y colaterales), sustrato utilizado, diámetro del sustrato, diámetro de luz diurna y altura del nido en relación al suelo. La investigación se realizó en predios ubicados en el municipio de Picuí, microrregión del Seridó Oriental Paraibano. Se realizó un Análisis de Varianza (ANOVA) y se comparó la media mediante la prueba de Tukey $(\mathrm{p} \leq 0.05)$. En esta microrregión se identificaron dos especies de Xylocopa: X. (Neoxylocopa) grisescens Lepeletier, 1841 y X. (Neoxylocopa) cearenses Ducke, 1910). Estas especies mostraron hábitos de anidación en anacardos (Annacardium occidentale), umburana (Commiphora leptophloeos), mulungú (Erythrina mulungu) y cowberry (Tabebuia caraiba). Estas abejas tienen una preferencia de anidación hacia el punto colateral del suroeste (SW).

Palabras clave: Anidación; Orientación magnética; Abejas nativas.

\section{Introdução}

O estudo das abelhas vem ganhando relevância nos últimos anos pela importância que desempenham na natureza como produtoras de mel e, principalmente, como agentes polinizadores, tanto em áreas agrícolas quanto naturais. Entre esses agentes polinizadores, destaca-se as abelhas do gênero Xylocopa, pertencentes à família Apidae, popularmente conhecidas como mamangavas, mamangabas, mamangás, mangangavas, mangavas ou mangangás (Santos \& Costa-Neto, 2012). Há ainda outros sinônimos, não tão comuns, como "mamangavas de toco" ou "abelhas carpinteiras", pois nidificam em troncos de árvores mortas ou qualquer parte vegetal em decomposição (Camillo \& Garófalo, 1982; Oliveira Filho \& Freitas, 2003; Pereira \& Garófalo, 2010; Almeida, 2016).

De acordo com Freitas e Oliveira Filho (2001), há várias espécies de abelhas erroneamente confundidas com gênero Xylocopa. Entre essas espécies, destacam-se as abelhas do gênero Bombus (Família Apidae) onde muitas espécies fazem ninhos no chão; as pequenas mamangavas dos gêneros Lithurgus e Trichothurgus (Família Megachilidae) que cavam seus ninhos em madeira morta; as mamangavas anãs dos gêneros Pithitis e Ceratina (Família Anthophoridae); e as mamangavas dos gêneros Lestis e Proxylocopa (Família Anthophoridae). Segundo esses autores, existem mais de 730 espécies do gênero Xylocopa conhecidas no mundo e englobam abelhas volumosas, com algumas chegando a ter $4,5 \mathrm{~cm}$ de comprimento.

Algumas características são comuns a este gênero, a exemplo da coloração preta e brilhante (Marchi \& Santos, 2013). Várias espécies exibem dimorfismo sexual, em que os machos são naturalmente identificados (em relação às fêmeas) por sua pigmentação amarelo alaranjada (Freitas \& Oliveira Filho, 2001). Geralmente, abelhas Xylocopa spp. exibem hábito solitário (Bernardino, 2008), tipificado pela independência das fêmeas na preparação e suprimento de seus ninhos e pela inexistência de trabalho cooperativo, ainda que as fêmeas fiquem no ninho após emergência (Viana et al., 2002). Ocasionalmente, essas abelhas podem exibir sobreposição de progênie e tolerância ao aparecimento de coespecíficos no ninho, fato que as tornam conhecidas como "facultativamente sociais" e as colônias designadas de "quase-sociais" (Bernardino, 2008). Algumas espécies podem formar associações entre mãe e filha ou entre irmãs, apresentando comportamento e interações sociais que evoluem à medida que as abelhas amadurecem fisiologicamente (Freitas \& Oliveira Filho, 2001).

Bernardino (2008) justifica a eventualidade de ocorrer mais de um adulto de Xylocopa spp. no mesmo ninho, pela necessidade de um período para maturação por parte dos indivíduos emergentes, os quais o abandonariam após esse período. Apresentam, também, filopatia, que é a tendência de fêmeas permanecerem no local de origem reutilizando o ninho materno ou fundando novos ninhos (Junqueira, 2016).

Durante o processo de nidificação as mamangavas só tentam cavar seus próprios ninhos após terem acasalado e mesmo quando reutilizam ninhos de gerações anteriores, normalmente constroem suas próprias células ou galerias (Freitas \& Oliveira Filho, 2001; Oliveira et al., 2014). Em casos em que o ninho não foi construído pela mesma espécie, geralmente as abelhas fazem algumas correções, principalmente em diâmetro e comprimento das cavidades. 
As fêmeas de Xylocopa spp., em processo reprodutivo, inspecionam vários possíveis sítios antes de decidirem-se por algum. Essa escolha pode ser motivada pela existência de outros ninhos ativos, uma vez que algumas espécies raramente fazem o orifício de nidificação próximo a outros ninhos, diferentemente de outras abelhas (Freitas \& Oliveira Filho, 2001; Marchi \& Melo, 2010). A escolha de um hospedeiro vegetal para nidificação é executada de forma solitária; após a abertura das cavidades do ninho, iniciam suas atividades de construção e aprovisionamento de células de cria (Bernardino, 2008; Oliveira et al., 2014). Geralmente, esses ninhos são construídos em madeira morta, seca e em estágio inicial de decomposição (Freitas \& Oliveira Filho, 2001; Schlindwein et al., 2003). Algumas espécies, no entanto, constroem ninhos em partes vivas de árvores (Freitas \& Oliveira Filho, 2001).

O diâmetro do alvado, escavado pelas abelhas, está diretamente relacionado ao tamanho e características inerentes a espécie da abelha. As fêmeas de Xylocopa spp. tendem a selecionar o diâmetro da cavidade em função de seu próprio tamanho (Pereira \& Garófalo, 2010). Por outro lado, o diâmetro do tronco - no processo de nidificação - é uma característica bastante particular e pode variar de acordo com a espécie vegetal e da abelha. Siqueira et al. (2014), por exemplo, identificaram o maior número de nidificação em troncos com 3,0 a 5,0 cm de diâmetro, enquanto que Viana et al. (2002), encontraram diâmetro do substrato utilizado por Xylocopa spp com variações entre 4 e $17 \mathrm{~cm}$.

Pereira e Garófalo (2010), em estudos de nidificação dessas abelhas em bambu, encontraram que os diâmetros de 1,9 e 2,0 cm foram os mais utilizados pelas espécies $X$. grisescens e $X$. frontalis. Bernardino (2008) recomenda o uso de substratos com circunferências maiores que $20 \mathrm{~cm}$ para uma melhor acomodação de canais e células de cria e, desta forma, contribuir de maneira expressiva no desenvolvimento populacional; já os colmos de bambu devem ter um diâmetro interno entre 1,90 e 2,40 $\mathrm{cm}$ e paredes secundárias com espessura maior que $0,4 \mathrm{~cm}$.

No processo de nidificação, o comprimento do tronco é outra característica relevante, pois o tamanho do substrato pode interferir no tamanho e arquitetura do ninho, inviabilizando sua reutilização. Ou seja, os ninhos em troncos de maior comprimento possibilitam as fêmeas fazerem várias galerias, o que indica que mais células possam ser adicionadas com o tempo e agregar várias gerações (Pereira \& Garófalo, 2010).

Quanto à altura dos ninhos nas plantas, Siqueira et al. (2014) observaram um maior número em troncos com uma altura variável de 130cm a $290 \mathrm{~cm}$ do solo. Viana et al. (2014), entretanto, verificaram uma maior periodicidade de ninhos de Xylocopa spp. em hospedeiros vegetais com altura entre 140 a $320 \mathrm{~cm}$ em relação ao solo.

$\mathrm{O}$ estudo sobre o comportamento de abelhas analisando a influência dos campos magnéticos na orientação vem crescendo nos últimos anos. As primeiras observações foram realizadas com abelhas Apis mellifera L., onde constatou-se dois tamanhos diferentes de magnetita no abdômen que proporcionaria modelos para o mecanismo de sua orientação (Macêdo, 2017). Não se sabe ao certo quais meios de recepção são capazes de detectar a orientação e como é realizada a transmissão de informações ao sistema nervoso para que haja a escolha do orifício de nidificação das abelhas (Acosta-Avalos et al., 2001; Vaz, 2015).

A orientação das fêmeas de Xylocopa spp. é bastante controversa. Anzenberger (1986), por exemplo, afirma que as abelhas reconhecem seus ninhos pelo olfato; não somente através do odor do substrato vegetal ou do alimento, mas, principalmente, através do cheiro individual. Por outro lado, Hefetz (1992) e Marchi (2008) sugerem que as secreções podem contribuir ao reconhecimento dos mesmos.

Áreas de preservação ambiental possuem espécies vegetais nativas, provedoras de alimento, que são excelentes hospedeiras para a nidificação de abelhas (Chaves-Alves, 2009). Abelhas do gênero Xylocopa geralmente não demonstram especialização em relação ao tipo de hospedeiro vegetal para nidificação (Camillo \& Garófalo, 1982). Aparentemente, as características morfológicas da planta são os principais motivos de preferência. 
A identificação das espécies vegetais utilizadas por Xylocopa spp. para nidificação e obtenção de recursos alimentícios são de grande relevância no manejo e preservação destas abelhas, tanto em áreas naturais e agrícolas (Chaves-Alves et al., 2011). Em estudos de nidificação de abelhas no Estado de São Paulo, o hospedeiro vegetal mais frequentemente foi Eucalyptus sp.; os de menor regularidade foram: Caesalpinea sp. (X. frontalis e X. grisescens), Pinus sp. (X. suspecta e X. frontalis), Ricinus communis, Aspidosperma pyriocollum, Delonix regia, Euphorbia pulcherri (X. suspecta), Synadenium carinatum (X. suspecta, X. grisescens e X. suspecta) e Cajanus indicus (Oliveira et al., 2014). Em estudos realizados no Estado de Minas Gerais, verificou-se a presença de 79 ninhos de Xylocopa (X. suspecta e X. frontalis), sendo Ficus sp. a espécie que demonstrou maior atratividade a fêmeas de Xylocopa spp (46,34\%) dos substratos observados contendo ninhos (Oliveira et al., 2014).

No gênero Xylocopa existem 22 espécies pertencentes a quatro subgêneros: Dasyxylocopa, Neoxylocopa, Schonnherria e Stenoxylocopa (Santos, 2016). As espécies com maior prevalência no Brasil são: Xylocopa (Neoxylocopa) frontalis Olivier, 1789, X. (Neoxylocopa) brasilianorum Linnaeus, 1767, X. (Neoxylocopa) suspecta Moure e Camargo, 1988, X. grisescens (Lepeletier) e X. (Stenoxylocopa) artifex Smith, 1874 (Freitas \& Oliveira Filho, 2001; Santos, 2016). No estado da Paraíba podese encontrar: Xylocopa frontalis Olivier, 1789; X. (Neoxylocopa) grisescens Lepeletier, 1841; X. suspecta Moure e Camargo, 1842; X. varians Smith, 1874 e X. muscaria Fabricius, 1775 (Marchi \& Melo, 2010; Alves-dos-Santos, 2013; Bernardino, 2008; Santos, 2016).

Este trabalho teve como objetivo analisar a nidificação de abelhas Xylocopa spp. no Seridó Oriental Paraibano, levando em consideração: orientação de nidificação, substrato utilizado, diâmetro do substrato, diâmetro do alvado e altura do ninho em relação ao solo.

\section{Material e Métodos}

A pesquisa foi conduzida em três propriedades distintas, Sítio Olho D’água das Onças (SODO), Sítio Novo Horizonte (SNH) e Sítio Viração (SV), ambas do município de Picuí (Latitude 06 30' 38' S e Longitude 36 20’49" W) situado na microrregião do Seridó Oriental Paraibano, no período de maio de 2017 a julho de 2018. Tratam-se de áreas agrícolas bastante antropizadas onde apenas o SV apresenta remanescente de vegetação nativa.

Nestas propriedades, através de caminhadas em toda extensão territorial, foram identificados ninhos ativos e/ou inativos de Xylocopa spp. nas espécies vegetais disponíveis. O critério de identificação desses ninhos foi a análise de espécies vegetais em estágio inicial ou final de senescência e também de apodrecimento.

Foram analisadas diversas árvores, das quais quatro espécies vegetais apresentaram nidificação por Xylocopa spp., sendo elas: cajueiro (Annacardium occidentale), umburana (Commiphora leptophloeos), mulungú (Erythrina mulungu) e caubeira (Tabebuia caraíba). Após a identificação dos ninhos foram visualizados e anotados os seguintes aspectos de nidificação: altura do alvado (ninho), diâmetro do alvado, diâmetro do tronco, orientação magnética de nidificação e distância entre nidificações (em casos de mais de um ninho no mesmo substrato).

A altura do ninho, diâmetro do alvado, diâmetro do tronco e distância entre as nidificações foram medidas com o auxílio de uma fita métrica Starret ${ }^{\circledR}$. A orientação magnética do orifício de nidificação foi realizada com o auxílio do aplicativo de bússola Compass Free $e^{\circledR}$, em celular LG X Scren ${ }^{\circledR}$. Os ninhos foram mapeados com suas respectivas coordenadas geográficas através de um GPS Garmim ${ }^{\circledR}$ e documentados por meio de fotografias. Realizou-se a captura de duas abelhas do gênero Xylocopa, as quais foram identificadas no Departamento de Sistemática e Ecologia (DSEC) da Universidade Federal da Paraíba (UFPB).

Para análise estatística, os dados foram organizados em três tratamentos: orientação magnética, espécie vegetal e área de coleta, correlacionados à altura do ninho, o diâmetro do alvado e o diâmetro do tronco. Após a organização dos dados em planilha no Microsoft Excel ${ }^{\circledR}$ 2013, realizou-se uma Análise de Variância (ANOVA) e a média comparada pelo teste de Tukey $(p \leq 0,05)$ através do programa estatístico $\mathbf{R}^{\circledast}$. 


\section{Resultados e Discussão}

As abelhas do gênero Xylocopa, encontradas na microrregião do Seridó Oriental Paraibano, demonstraram preferência de nidificação em espécies vegetais que apresentavam mortalidade total ou parcial. Observou-se a tendência de agregação nas nidificações, onde o mesmo substrato vegetal apresenta-se nidificado por várias abelhas, indicando o estabelecimento de várias gerações em um mesmo hospedeiro. Este comportamento foi registrado por Camillo \& Garófalo (1982), os quais afirmam que dependendo da espécie, algumas vezes mãe e filha, ou irmãs, associam-se, reutilizando o mesmo ninho. Neste caso, tanto a filha em relação à mãe, quanto a(s) irmã(s) mais nova(s) em relação à irmã mais velha podem, inicialmente, ajudar apenas coletando alimento para aprovisionar uma célula de cada vez; sendo a postura de responsabilidade da mãe, no primeiro caso, ou da irmã mais velha, no segundo. Isso pode ser considerado, também, como reuso dos ninhos, quando as fêmeas nele produzidas permitem a organização algum tipo de relação entre elas, podendo ser considerada como uma associação "eussocial primitiva" (com sobreposição de gerações - mãe e filha) ou "semi-social" (entre irmãs) (Oliveira et al. 2014). Estes mesmos autores sugerem que a presença da sobreposição de gerações e sua consequente divisão reprodutiva de atividade, constituem-se em um indicador de que abelhas (fêmeas) do gênero Xylocopa podem exibir uma longevidade superior em relação a fêmeas de outras espécies de abelhas solitárias.

Com relação à influência das espécies vegetais na nidificação de abelhas Xylocopa spp a partir do diâmetro do alvado (Figura 1), do diâmetro do tronco (Figura 2) e da altura do ninho (Figura 4) na microrregião do Seridó Oriental Paraibano, observa-se que houve diferença significativa apenas nos parâmetros diâmetro do tronco e altura do ninho.

O diâmetro do alvado das espécies vegetais estudadas não difere (significativamente) em sua influência na nidificação de Xylocopa spp. Todavia, o maior diâmetro foi constatado para espécie cajueiro $(1,92 \mathrm{~cm})$ e o menor para umburana $(1,73 \mathrm{~cm})$ [Figura 1]. Viana et al. (2002), constataram um diâmetro do orifício de entrada de aproximadamente 1,79 cm., enquanto Bernardino (2008) constatou uma diferença entre o diâmetro de nidificação em ninhos de $X$. ordinaria (variando de variando de 1,06 a $1,70 \mathrm{~cm}$ ) es de $X$. frontalis (com variação de 1,33 a 2,16cm).

Neste estudo, encontrou-se uma variação de $1,55 \mathrm{~cm}$ a $1,95 \mathrm{~cm}$ para o diâmetro do alvado na nidificação de Xylocopa spp. no Seridó Oriental Paraibano (Figura 1). Viana et al. (2002) constataram um diâmetro do orifício de entrada de aproximadamente $1,79 \mathrm{~cm}$, ao passo que Bernardino (2008) constatou uma diferença entre o diâmetro de nidificação em ninhos de $X$. ordinaria (variando de variando de 1,06 a $1,70 \mathrm{~cm}$ ) es de $X$. frontalis (com variação de 1,33 a 2,16cm). 
Figura 1. Diâmetro do alvado $(\mathrm{cm})$ em relação aos substratos de nidificação, cajueiro (Annacardium occidentale), umburana (Commiphora leptophloeos), mulungú (Erythrina mulungu) e caubeira (Tabebuia caraíba), de Xylocopa spp. na microrregião do Seridó Oriental Paraibano.

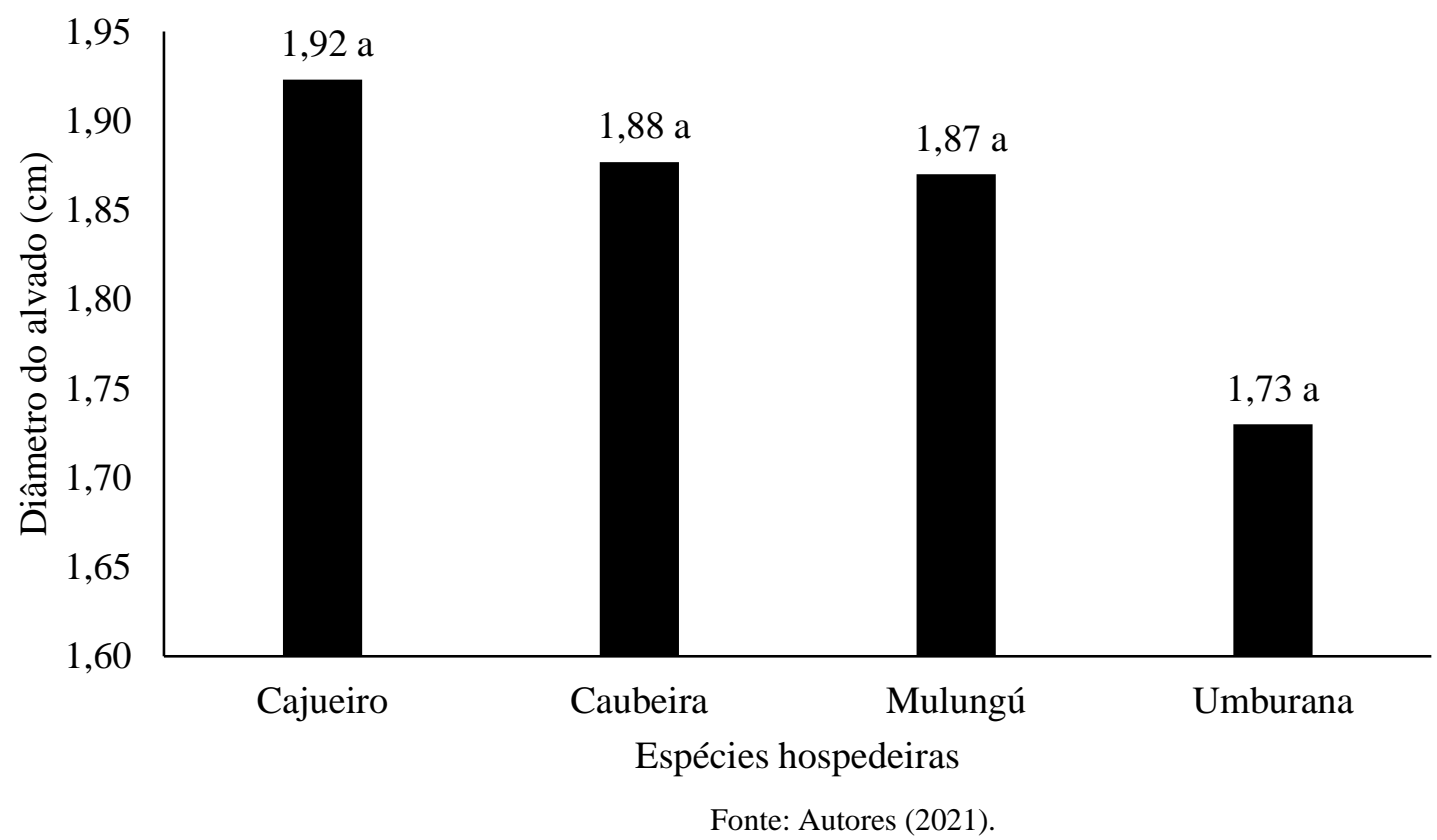

O diâmetro do tronco nidificado por Xylocopa spp. no Seridó Oriental Paraibano variou de 16,53 a 34,65 cm, onde a espécie vegetal umburana apresentou o menor diâmetro de tronco e o cajueiro o maior (Figura 2).

Figura 2. Diâmetro do tronco $(\mathrm{cm})$ em relação ao substrato de nidificação, cajueiro (Annacardium occidentale), umburana (Commiphora leptophloeos), mulungú (Erythrina mulungu) e caubeira (Tabebuia caraíba), de Xylocopa spp na microrregião do Seridó Oriental Paraibano.

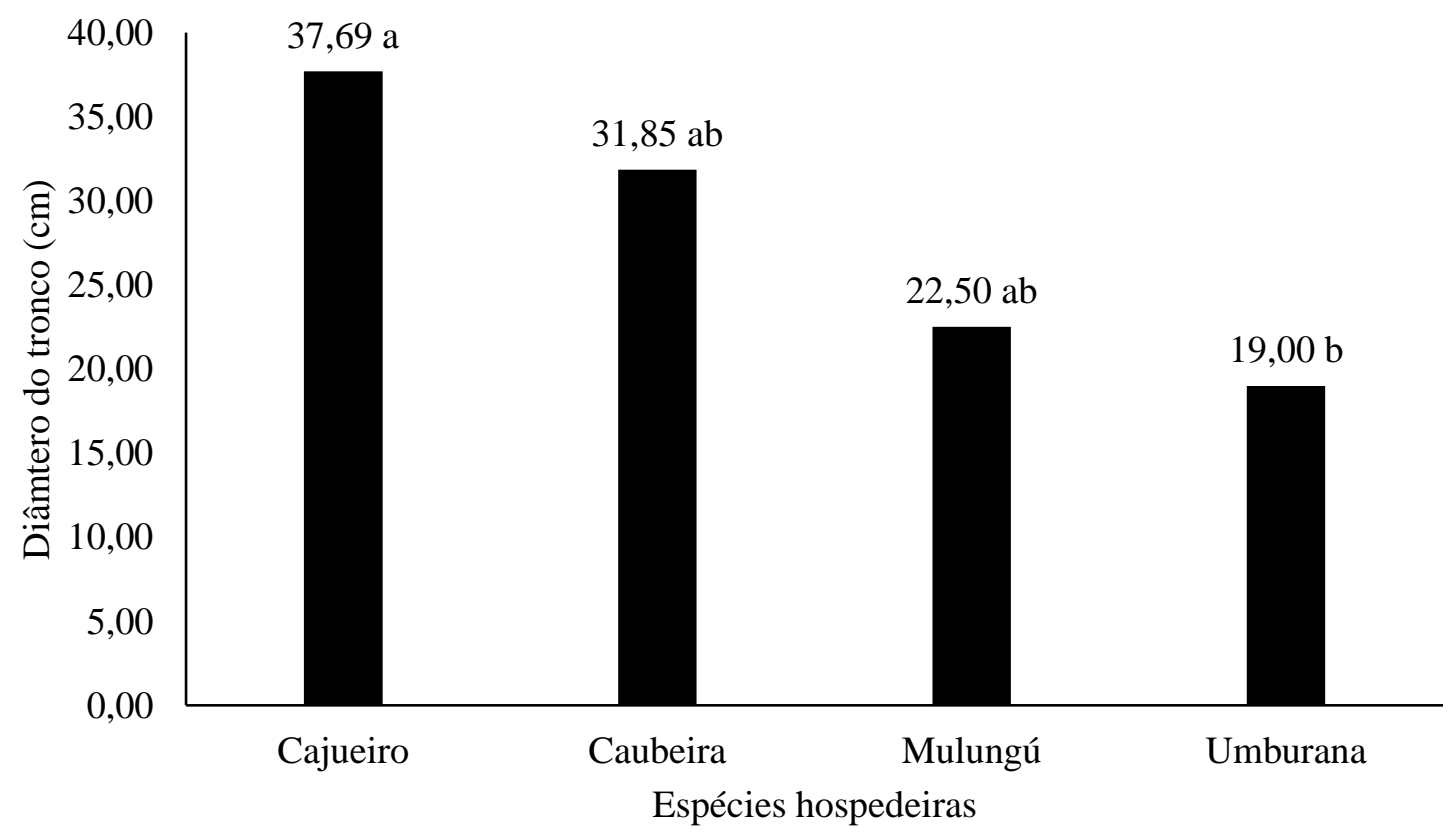

Fonte: Autores (2021). 
Apesar do diâmetro do tronco ser uma característica intrínseca da planta este poderia ser fator limitante para nidificação dessas abelhas, porém a variação é superior ao menor diâmetro nidificado por elas. Bernardino (2008) analisando o processo de nidificação $X$. ordinaria e $X$. frontalis afirma que ninhos de $X$. ordinaria são feitos com maior periodicidade em substratos com circunferência externa entre $10 \mathrm{~cm}$ e $20 \mathrm{~cm}$; e no caso de $X$. frontalis, nidificam com superior frequência em colmos de bambu com diâmetro interno variando entre $1,9 \mathrm{~cm}$ e $2,4 \mathrm{~cm}$. Viana et al. (2014) encontraram ninhos de Xylocopa spp. com diâmetro variável entre 29 a $60 \mathrm{~cm}$.

Para Viana et al. (2002) e Marchi (2008), diâmetros entre 4 e $17 \mathrm{~cm}$ reduz a quantidade de ninhos no mesmo substrato, uma vez que o espaço se torna pequeno para a preparação de outros ninhos sem a eventual invasão de ninhos pré-existentes. Entretanto, o diâmetro do tronco das espécies vegetais estudadas apresentou diferença significativa ao nível de 5\% de probabilidade (Figura 2) na nidificação de Xylocopa spp. Os maiores diâmetros foram apresentados por cajueiro, caubeira e mulungú e o menor por umburana. Macêdo (2017), por outro lado, em estudo realizado no Curimataú Paraibano, encontrou que as maiores nidificações de (outras) abelhas indígenas (de menor porte) são realizadas em cajueiros hospedeiros que apresentavam maiores diâmetros.

A distância entre ninhos (Figura 3), em um mesmo substrato vegetal, pode indicar o comprimento e arquitetura de nidificação de Xylocopa spp, pois esta medida orienta o início e o fim da construção do ninho. Essa informação torna-se relevante no entendimento do tamanho mínimo do substrato vegetal que servirá de hospedeiro à nidificação dessa abelha.

Figura 3. Distância entre ninhos $(\mathrm{cm})$ de Xylocopa spp em relação ao substrato de nidificação, umburana (Commiphora leptophloeos), cajueiro (Annacardium occidentale), caubeira (Tabebuia caraíba) e mulungú (Erythrina mulungu) na microrregião do Seridó Oriental Paraibano.

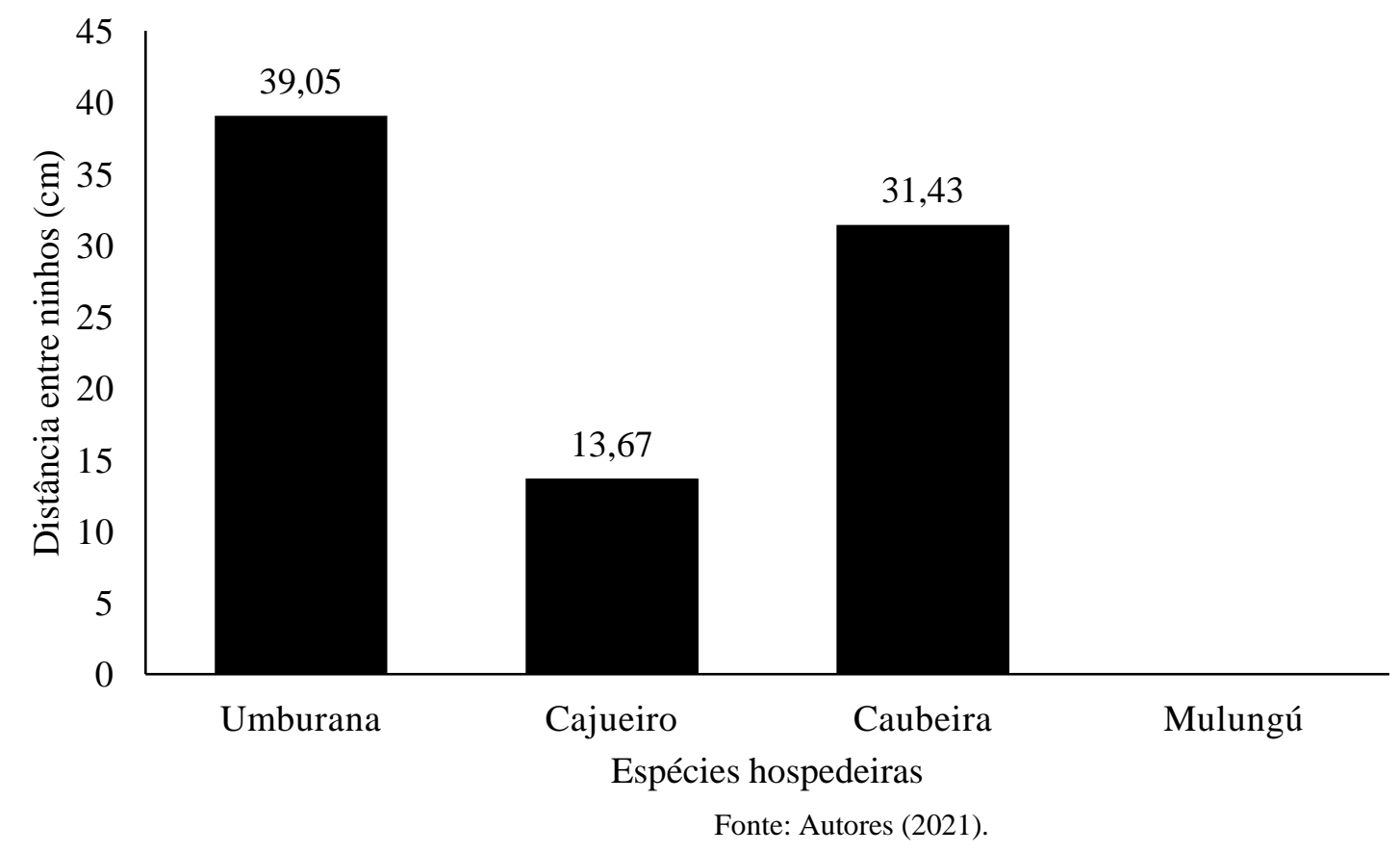

Bernardino (2008) constatou, por exemplo, que os ninhos de Xylocopa ordinaria foram escavados em hospedeiros vegetais que exibiam comprimento entre 35 e $100 \mathrm{~cm}$ e circunferência externa entre 10 e $20 \mathrm{~cm}$, diferentemente do constatado nesta pesquisa (Figura 3).

A altura do ninho é uma estratégia de defesa utilizada por alguns animais contra o possível ataque de predadores. No caso da nidificação de Xylocopa spp no Seridó Oriental Paraibano, constatou-se que a altura está diretamente relacionada ao tamanho do substrato, pois suas nidificações variaram de 241,61 a 429,46 cm de altura (Figura 4). 
Figura 4. Altura do ninho (m) em relação ao substrato de nidificação, umburana (Commiphora leptophloeos), cajueiro (Annacardium occidentale), caraibeira (Tabebuia caraíba) e mulungú (Erythrina mulungu) na microrregião do Seridó Oriental Paraibano.

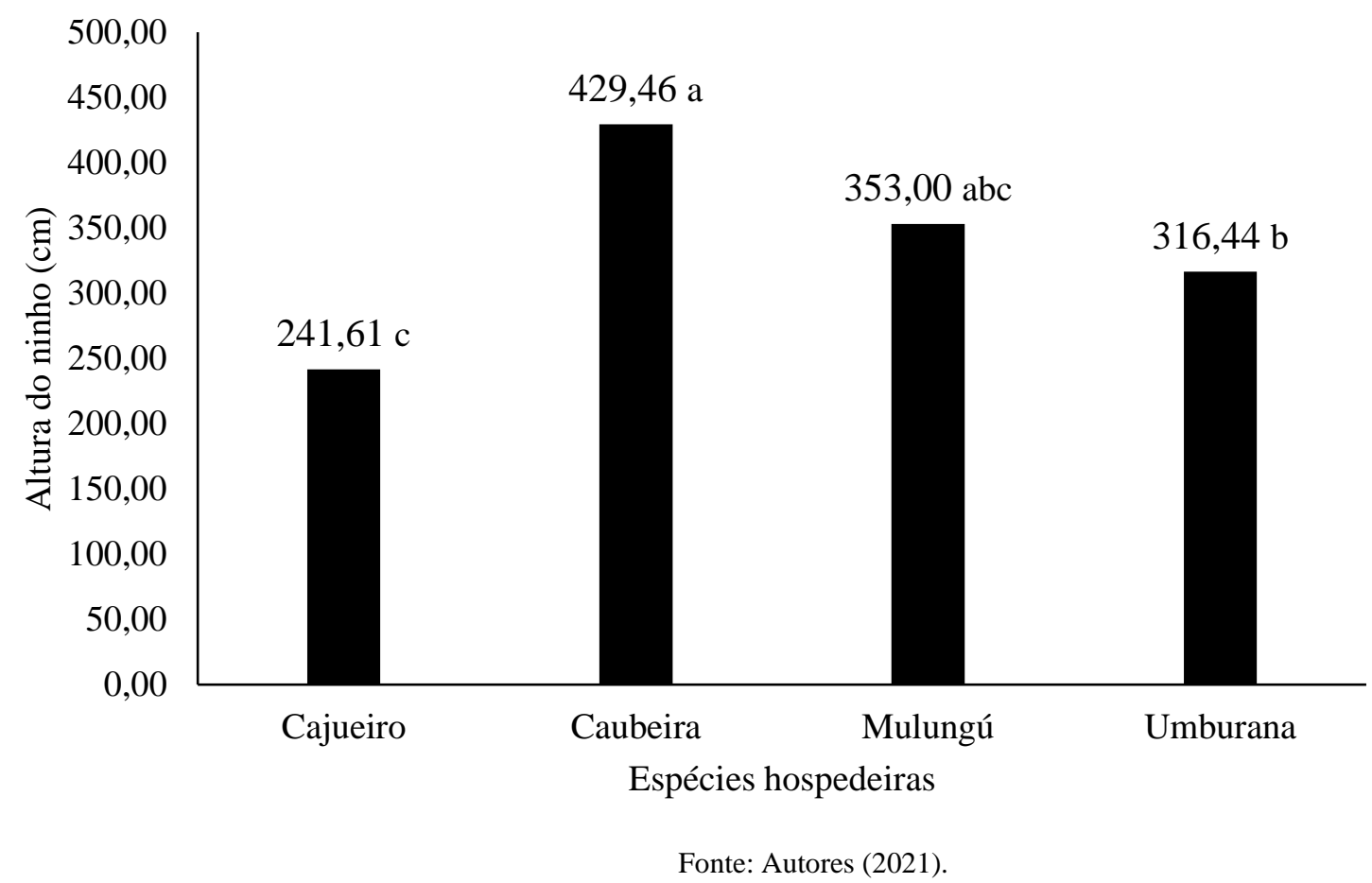

Quando se compara a altura dos ninhos em relação a espécie vegetal (Figura 4), observa-se que estes também sofreram diferença significativa, onde as nidificações por Xylocopa foram mais altas em caubeira $(429,46 \mathrm{~cm})$, mulungú $(353,00 \mathrm{~cm})$ e umburana $(316,44 \mathrm{~cm})$, enquanto os mais baixos foram identificados na espécie vegetal cajueiro (241,61 cm).

O comportamento de nidificação da Xylocopa spp no Seridó Oriental da Paraíba assemelha-se aos dados encontrados por Siqueira et al. (2014), com uma maior nidificação em troncos com uma altura de $130 \mathrm{~cm}$ a $290 \mathrm{~cm}$ (em relação ao solo); e entre 140 a $320 \mathrm{~cm}$ (Viana et al., 2014). Para Chaves-Alves et al. (2011), o maior número de ninhos ativos e inativos foram encontrados a uma altura menor que quatro metros de altura e uma circunferência entre $15 \mathrm{~cm}$ e $90 \mathrm{~cm}$.

Analisando a preferência de nidificação quanto à orientação magnética no Seridó Oriental Paraibano, obteve-se que os maiores índices de nidificações ocorreram nas posições: Sudoeste (SW), 23,5 \%; Norte (N), 12,3 \%; Noroeste (NW), 17,3\%; Sudeste (SE), 17,3\%; e Sul (S), (13,6\%); e as menores: Nordeste (NE), 3,7\%; Leste (E), 6,2\%; e Oeste (W), 6,2 \%, conforme (Figura 5). 
Figura 5. Orientação magnética de nidificação de Xylocopa spp na microrregião do Seridó Oriental Paraibano.

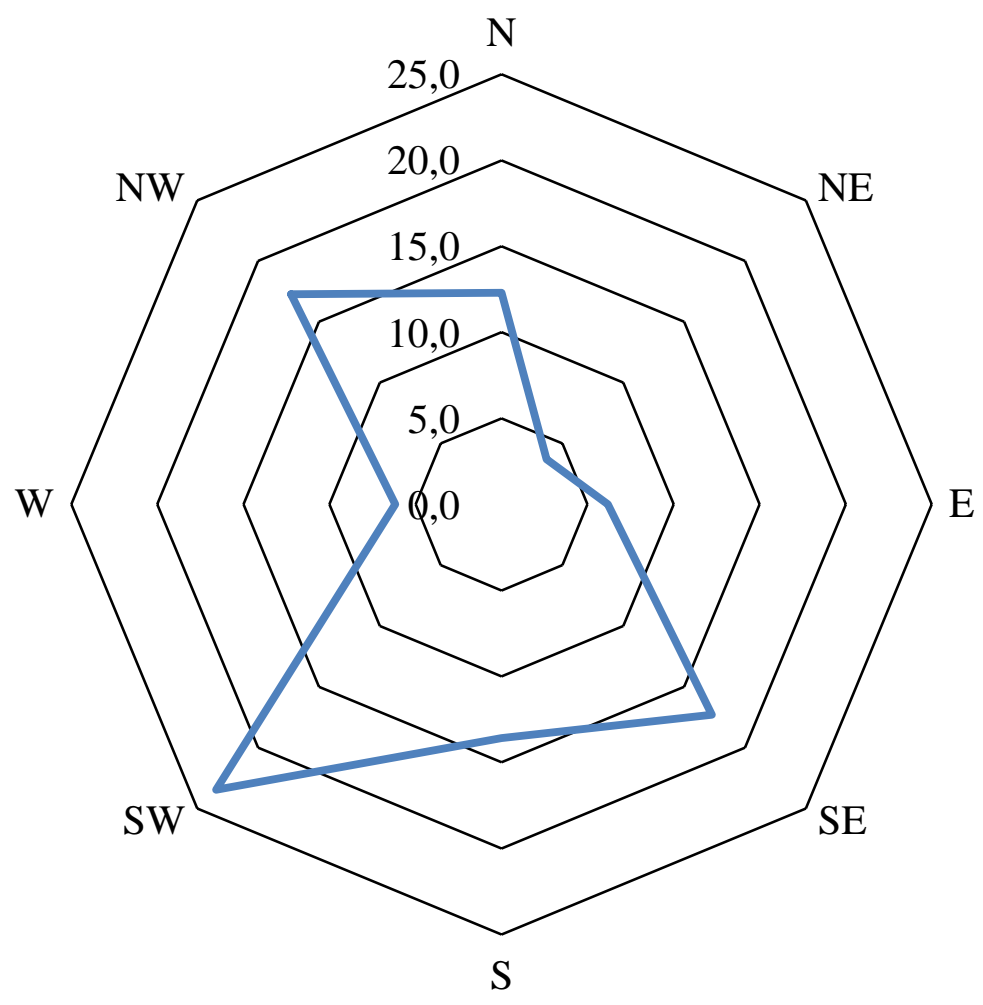

Fonte: Autores (2021).

De acordo com Vaz (2015), não se sabe ao certo se existe alguma influência dos campos magnéticos da terra em relação à escolha do orifício de nidificação das abelhas. Macêdo (2017) ao analisar a preferência de orientação magnética das melíponas encontradas na microrregião do Curimataú Paraibano obteve uma preferência para os pontos cardeais e colaterais mais ao norte. Ou seja, Norte (N) 20\%, Oeste (O) 20\% e Leste (L) 8,33\% e colaterais nordeste (NE) 21,67\% e noroeste (NO) 13,33\%. Os menores resultados para orientação magnética foram observados para as posições sudeste (SE), 3,33\%; Sul (S), 6,67\%; e sudoeste (SO), 6,67\%. Por outro lado, Vaz (2015) em experimento realizado com caixas octogonais obteve que abelha Frieseomelitta dispar tiveram uma frequência maior de entrada e saída pelo orifício Leste (E) e menor frequência para o ponto cardeal Sul (S).

Martins et al. (2012) em seus estudos sobre a frequência de nidificação de vespas e abelhas solitárias em locais sombreados e não sombreados no estado da Paraíba, constataram a preferência de nidificação com a entrada não dirigida para o leste sob influência do vento, conforme estudado por Vaz (2015).

Esta constatação de preferência de nidificação (na natureza) de Xylocopa spp, pode ser de grande valia para agricultores (meliponicultores) e produtores de maracujazeiro amarelo (Passiflora edulis), pois o uso de colmeias racionais com o alvado direcionado para posição natural dessas abelhas (Sudoeste), pode prevenir o enxameamento e, como consequência, aumentar a polinização da cultura.

Para o Seridó Oriental Paraibano, constatou-se que as espécies vegetais utilizadas como substrato de nidificação foram: cajueiro (Annacardium occidentale), umburana (Commiphora leptophloeos), mulungú (Erythrina mulungu) e caubeira (Tabebuia caraiba) [Tabela 1]. Várias espécies vegetais podem servir como substrato para hospedar abelhas do gênero Xylocopa. As condições básicas para espécies vegetais servirem como substrato de nidificação para essas abelhas é que sua estrutura (galhos ou troncos) esteja seca ou em início de decomposição e tenham textura parcialmente porosa para favorecer a perfuração (Camillo \& Garófalo, 1982). A C. leptophloeos destaca-se como hospedeiro vegetal de várias espécies de abelhas nativas nas microrregiões do Curimataú (Macêdo et al., 2020) e Brejo do estado da Paraíba (Silva et al., 2021). 
Tabela 1. Espécies vegetais (Annacardium occidentale, Commiphora leptophloeos, Erythrina mulungu e Tabebuia caraíba) utilizadas por abelhas Xylocopa spp como substratos para nidificação na microrregião do Seridó Oriental paraibano. Médias com letras iguais não diferem estatisticamente pelo teste de Tukey $(\mathrm{p} \leq 0,05)$.

\begin{tabular}{lcccc}
\hline Espécie & $\begin{array}{c}\mathbf{N}^{\mathbf{0}} \text { de } \\
\text { Nidificações }\end{array}$ & $\begin{array}{c}\overline{\mathbf{x}} \\
\text { Diâmetro do } \\
\text { Alvado }(\mathbf{c m})\end{array}$ & $\begin{array}{c}\overline{\mathbf{x}} \\
\text { Diâmetro do } \\
\text { tronco }(\mathbf{c m})\end{array}$ & $\begin{array}{c}\overline{\mathbf{x}} \\
\text { Altura do ninho (cm) }\end{array}$ \\
\hline Umburana & 30 & $1,73 \mathrm{a}$ & $19,00 \mathrm{~b}$ & $316,44 \mathrm{~b}$ \\
\hline Cajueiro & 27 & $1,92 \mathrm{a}$ & $37,69 \mathrm{a}$ & $241,61 \mathrm{c}$ \\
\hline Caubeira & 22 & $1,88 \mathrm{a}$ & $31,85 \mathrm{ab}$ & $429,46 \mathrm{a}$ \\
\hline Mulungú & 2 & $1,87 \mathrm{a}$ & $22,50 \mathrm{ab}$ & $353,00 \mathrm{abc}$
\end{tabular}

Fonte: Autores (2021).

No gênero Xylocopa os indivíduos de uma mesma espécie podem escolher entre um material tenro e fácil de escavar, onde poderão fazer um ninho menos durável, ou um material mais duro que oferecerá melhor proteção (Freitas \& Oliveira Filho, 2001; Pereira \& Garófalo, 2010). De acordo com Bernardino (2008), a mamangava apresenta sua escolha quanto ao substrato de nidificação associada a madeiras secas, leves e macias (sem fissura), e que possam ser prontamente escavadas. Schlindwein et al. (2003) explicam que existem espécies de Xylocopa que são ligadas a determinado grupo de vegetais muito mais pela facilidade de nidificação do que pelo aspecto de fonte de alimento. Até mesmo tronco de coqueiro, galhos de amendoeira e sisal, que possuem textura macia, podem ser favoráveis à perfuração de seus ninhos (Viana et al., 2014).

Na microrregião do Seridó Oriental Paraibano, foram coletadas e identificadas duas espécies de Xylocopa: a Xylocopa (Neoxylocopa) grisescens Lepeletier, 1841 e a Xylocopa (Neoxylocopa) cearenses Ducke, 1910. De acordo com Viana et al. (2014) as fêmeas de $X$. grisescens possuem um comprimento medianto total de 31,70 $\pm 2,52$ mm de comprimento total, 11,66 \pm 0,40 mm de largura do tórax e 9,21 \ 0,26 mm de largura da cabeça. Essas duas espécies apesar de apresentarem hábitos semelhantes, morfologicamente apresentam diferença no tamanho e consequentemente diâmetros de nidificação.

O fato dessas duas espécies de abelhas nidificarem em um mesmo substrato, pode estar relacionada ao observado por Marchi (2008) que afirma que a escolha de um local para a nidificação pode ter a influência de outros ninhos ativos de Xylocopa, havendo casos em que algumas espécies nunca nidificam próximo a outros ninhos, enquanto que há outras espécies em que as agregações são frequentes. Gerling et al. (1989) explicam que tal comportamento pode estar ligado ao arranjo do material de construção dos ninhos, mas a natureza dos substratos escolhidos ainda é obscura.

Com relação à influência das espécies vegetais na nidificação de abelhas Xylocopa spp a partir do diâmetro do alvado (Figura 6), do diâmetro do tronco (Figura 7) e da altura do ninho (Figura 9) na microrregião do Seridó Oriental Paraibano, observa-se que houve diferença significativa apenas nos parâmetros diâmetro do tronco e altura do ninho.

Gerling et al. (1989) afirmam que a associação de espécies de Xylocopa com hospedeiros de nidificação podem não ter associação com os hospedeiros vegetais de táxons afins e, sim, com controles ambientais tais como ocorrência e abundância destas estruturas vegetais ou às suas próprias características. Para Bernardino (2008), as abelhas demonstram suas escolhas relacionadas à dureza da madeira, seu estágio de conservação, características de comprimento e diâmetro dos galhos e troncos, bem como a sua abundância.

O diâmetro do alvado das espécies vegetais estudadas não difere (significativamente) em sua influência na nidificação de Xylocopa spp. Todavia, o maior diâmetro foi constatado para espécie cajueiro e o menor para umburana (Figura 6). 
Figura 6. Influência das espécies vegetais, cajueiro (Annacardium occidentale), caubeira (Tabebuia caraíba), mulungú (Erythrina mulungu), e umburana (Commiphora leptophloeos), na nidificação de abelhas Xylocopa spp. em relação ao diâmetro do alvado. Médias com letras iguais não diferem estatisticamente pelo teste de Tukey $(\mathrm{p} \leq 0,05)$.

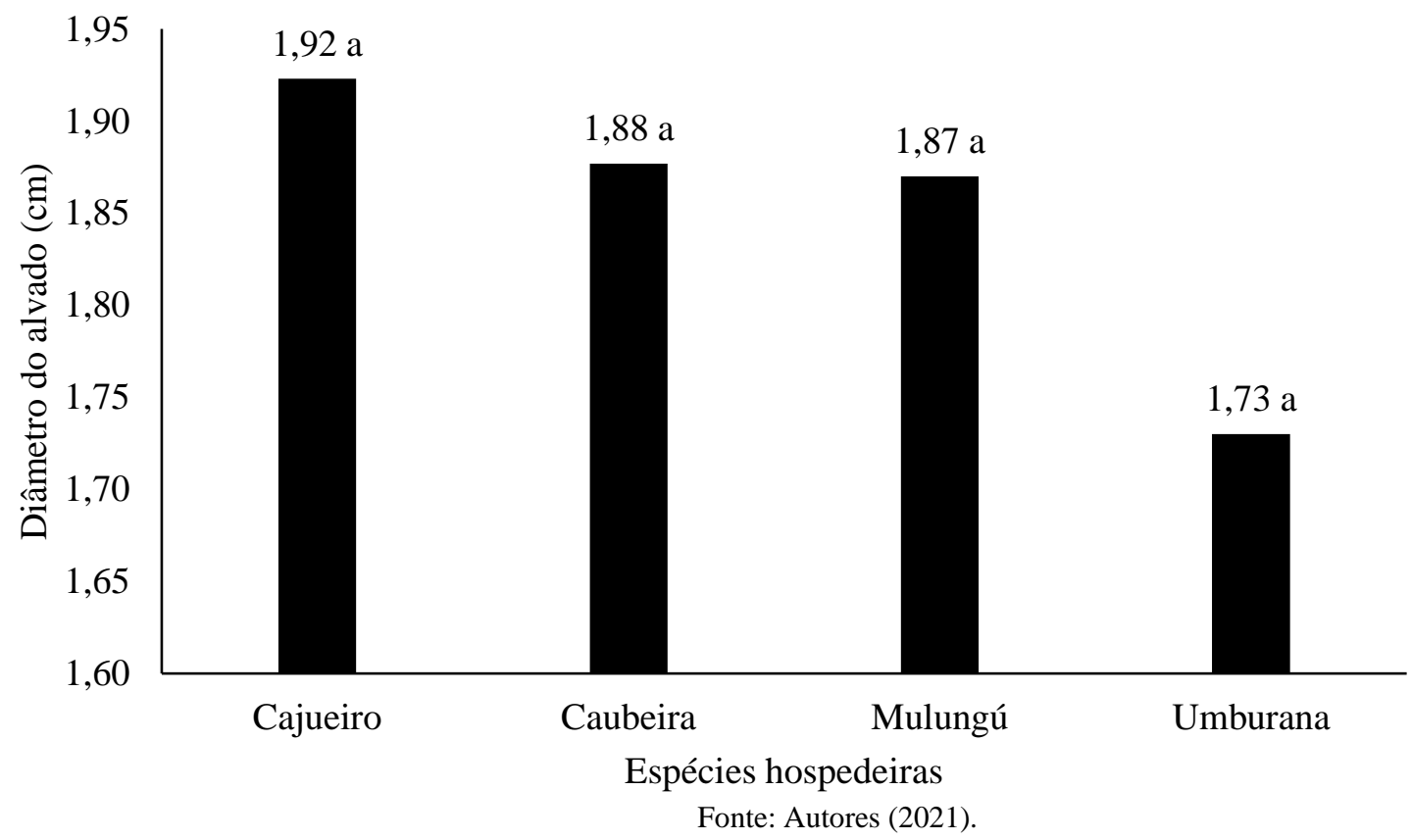

Entretanto, o diâmetro do tronco das espécies vegetais estudadas apresentou diferença significativa ao nível de 5\% de probabilidade (Figura 7) na nidificação de Xylocopa spp. Os maiores diâmetros foram apresentados pela caubeira, mulungú e umburana e o menor pelo cajueiro. Macêdo (2017), por outro lado, em estudo realizado no Curimataú Paraibano, encontrou que as maiores nidificações de (outras) abelhas indígenas (de menor porte) são realizadas em cajueiros hospedeiros que apresentavam maiores diâmetros. 
Figura 7. Influência das espécies vegetais, cajueiro (Annacardium occidentale), caubeira (Tabebuia caraíba), mulungú (Erythrina mulungu), e umburana (Commiphora leptophloeos), na nidificação de abelhas Xylocopa spp. em relação ao diâmetro do tronco. Médias com letras iguais não diferem estatisticamente pelo teste de Tukey $(\mathrm{p} \leq 0,05)$.

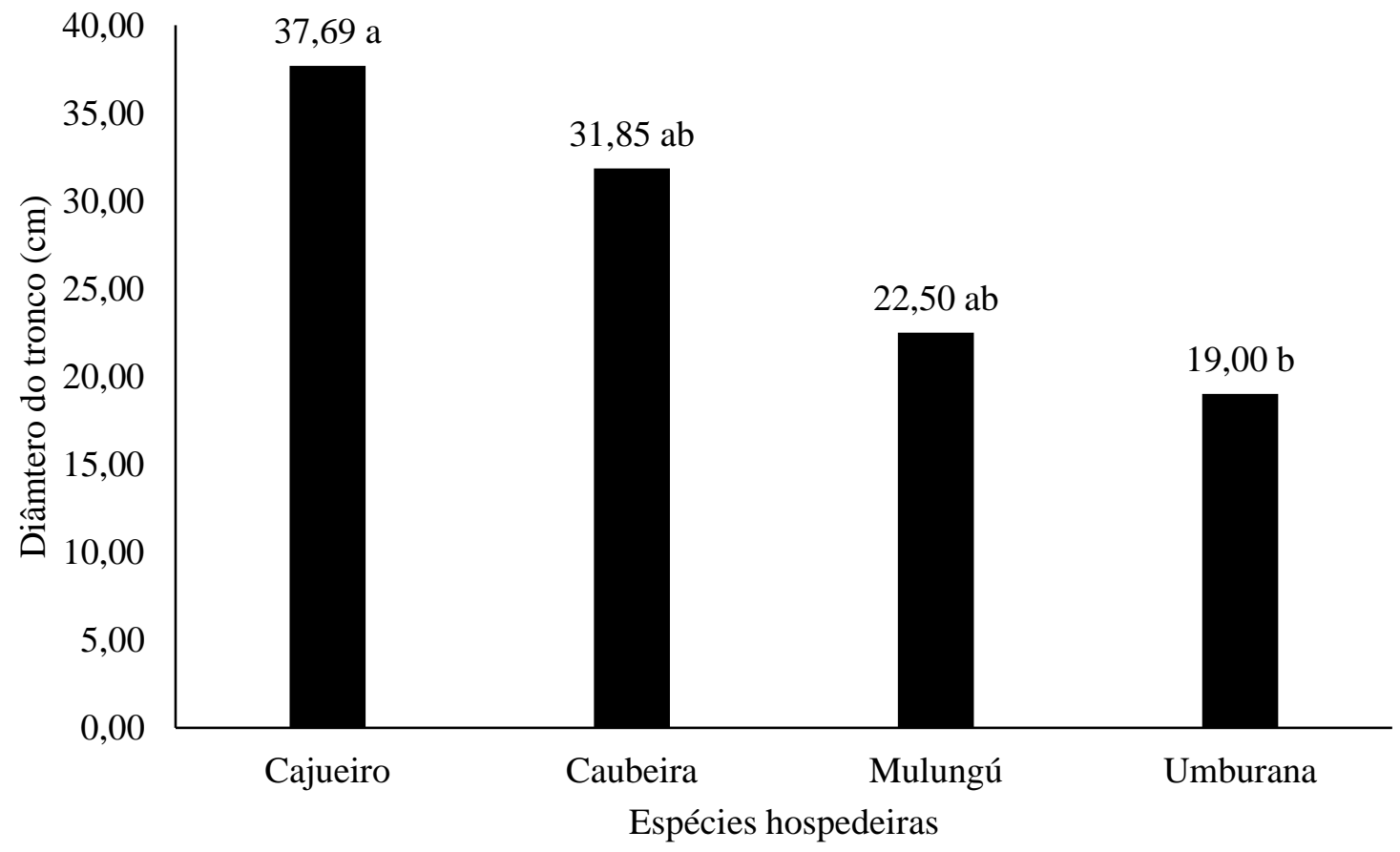

Fonte: Autores (2021).

Para Viana et al. (2002) e Marchi (2008), diâmetros entre 4 e $17 \mathrm{~cm}$ reduz a quantidade de ninhos no mesmo substrato, uma vez que o espaço se torna pequeno para a preparação de outros ninhos sem a eventual invasão de ninhos pré-existentes.

Quando se compara a altura dos ninhos em relação à espécie vegetal (Figura 8), observa-se que estes também sofreram diferença significativa, onde as nidificações por Xylocopa foram mais altas em caubeira e umburana, enquanto os mais baixos foram identificados na espécie vegetal cajueiro. 
Figura 8. Influência das espécies vegetais, cajueiro (Annacardium occidentale), caubeira (Tabebuia caraíba), mulungú (Erythrina mulungu), e umburana (Commiphora leptophloeos), na nidificação de abelhas Xylocopa spp em relação à altura do ninho. Médias com letras iguais não diferem estatisticamente pelo teste de Tukey $(\mathrm{p} \leq 0,05)$.

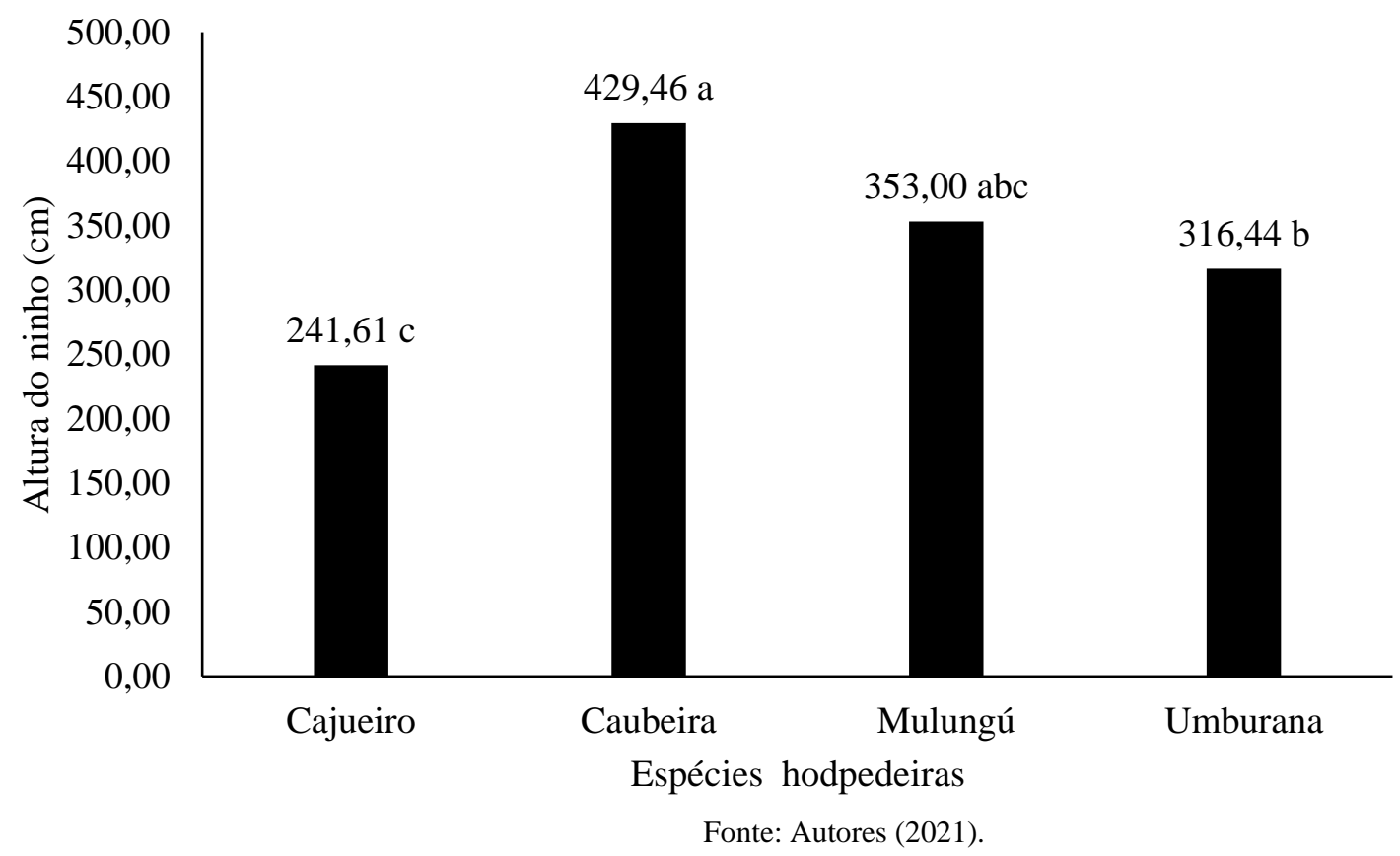

Para Chaves-Alves et al. (2011) o maior número de ninhos ativos e inativos foram encontrados a uma altura menor que quatro metros de altura e uma circunferência entre $15 \mathrm{~cm}$ e $90 \mathrm{~cm}$.

Verificou-se que a orientação magnética não exerceu influência estatística sob as nidificações de Xylocopa em relação ao diâmetro do alvado, diâmetro do tronco e altura do ninho na microrregião do Seridó Oriental Paraibano (Figuras 9, 10 e 11, respectivamente). Apesar da não haver diferença estatística em relação ao diâmetro do alvado (Figura 9), observa-se uma maior tendência de nidificação entre as posições NW (Noroeste) e N (Norte). Para Macêdo (2017) o diâmetro do orifício de entrada apresentou variação para os pontos que se encontravam voltados para o Leste, Sul e Noroeste. 
Figura 9. Influência da orientação magnética na nidificação de abelhas Xylocopa spp em relação ao diâmetro do alvado na microrregião do Seridó Oriental paraibano. Médias com letras iguais não diferem estatisticamente pelo teste de Tukey (p $\leq 0,05)$.

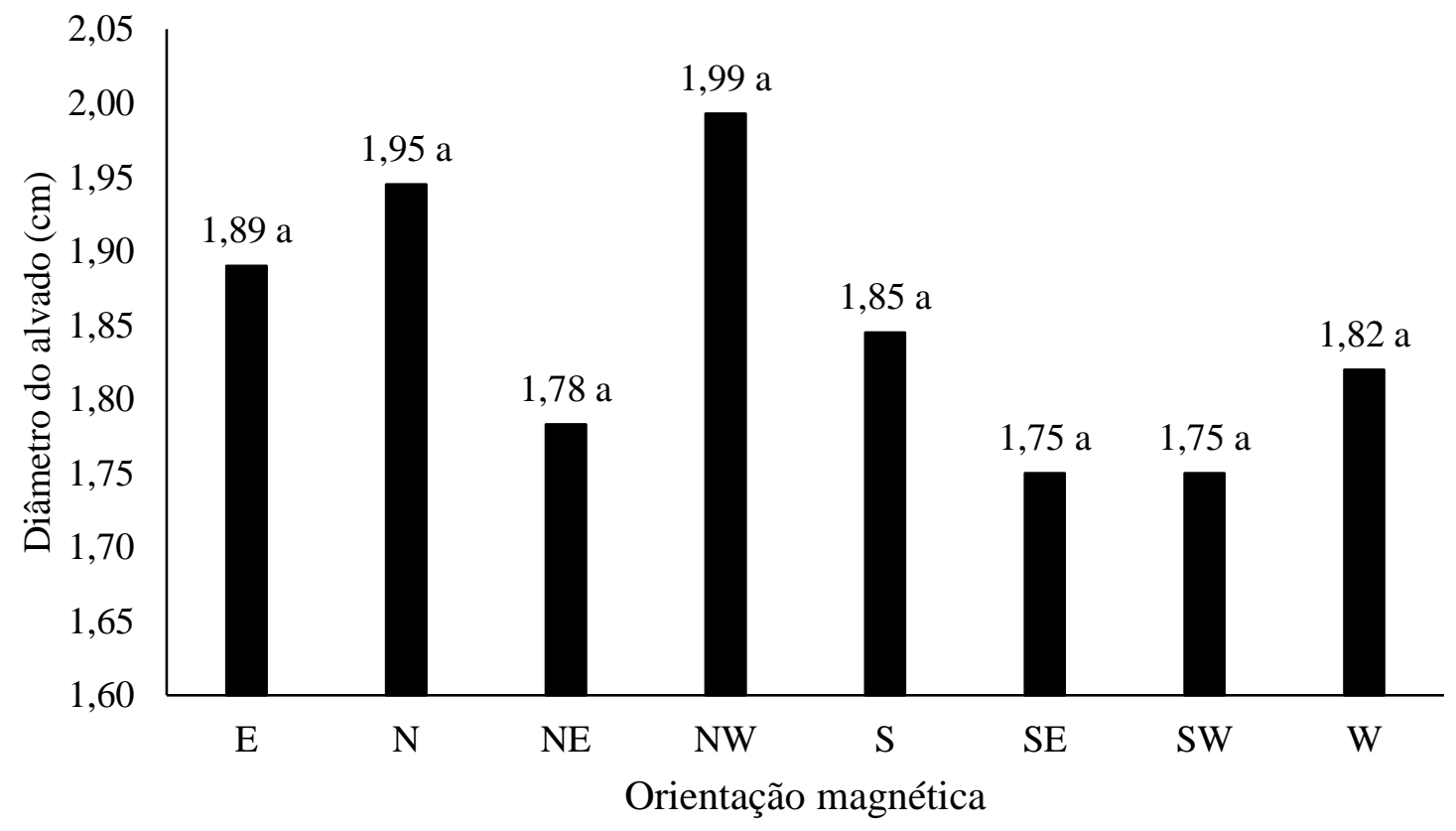

Fonte: Autores (2021).

Observa-se que a orientação magnética não sofre influência sob o diâmetro do tronco (Figura 10), do ponto de vista estatístico, mas observa-se uma certa variação com tendência maior para o ponto colateral Nordeste (NE) e uma menor variação para o ponto cardeal Leste (E), o que diferem dos resultados obtidos por Macêdo (2017).

Figura 10. Influência da orientação magnética na nidificação de abelhas Xylocopa spp em relação ao diâmetro do tronco na microrregião do Seridó Oriental paraibano. Médias com letras iguais não diferem estatisticamente pelo teste de Tukey ( $\mathrm{p} \leq 0,05)$.

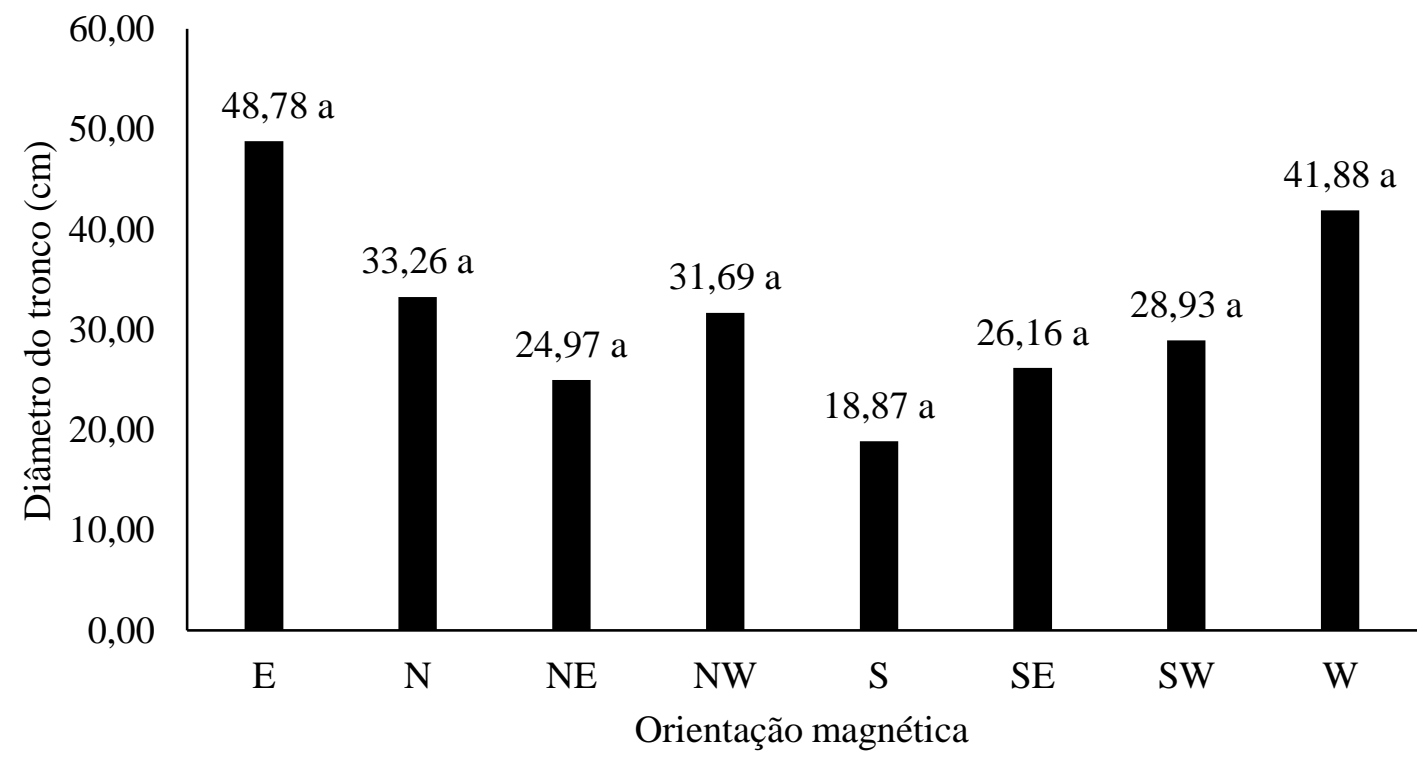

Fonte: Autores (2021).

Analisando a Influência da orientação magnética em relação à altura do ninho (Figura 11), constata-se que a variação foi a mesma exercida sob o diâmetro do tronco, uma vez que do ponto de vista estatístico não houve diferença, mas observa-se 
uma certa variação com tendência maior para o ponto colateral Nordeste (NE) e uma menor variação para o ponto cardeal Leste (E), o que também diferem dos resultados obtidos por Macêdo (2017).

Figura 11. Influência da orientação magnética na nidificação de abelhas Xylocopa spp em relação à altura do ninho na microrregião do Seridó Oriental paraibano. Médias com letras iguais não diferem estatisticamente pelo teste de Tukey ( $\mathrm{p} \leq 0,05$ ).

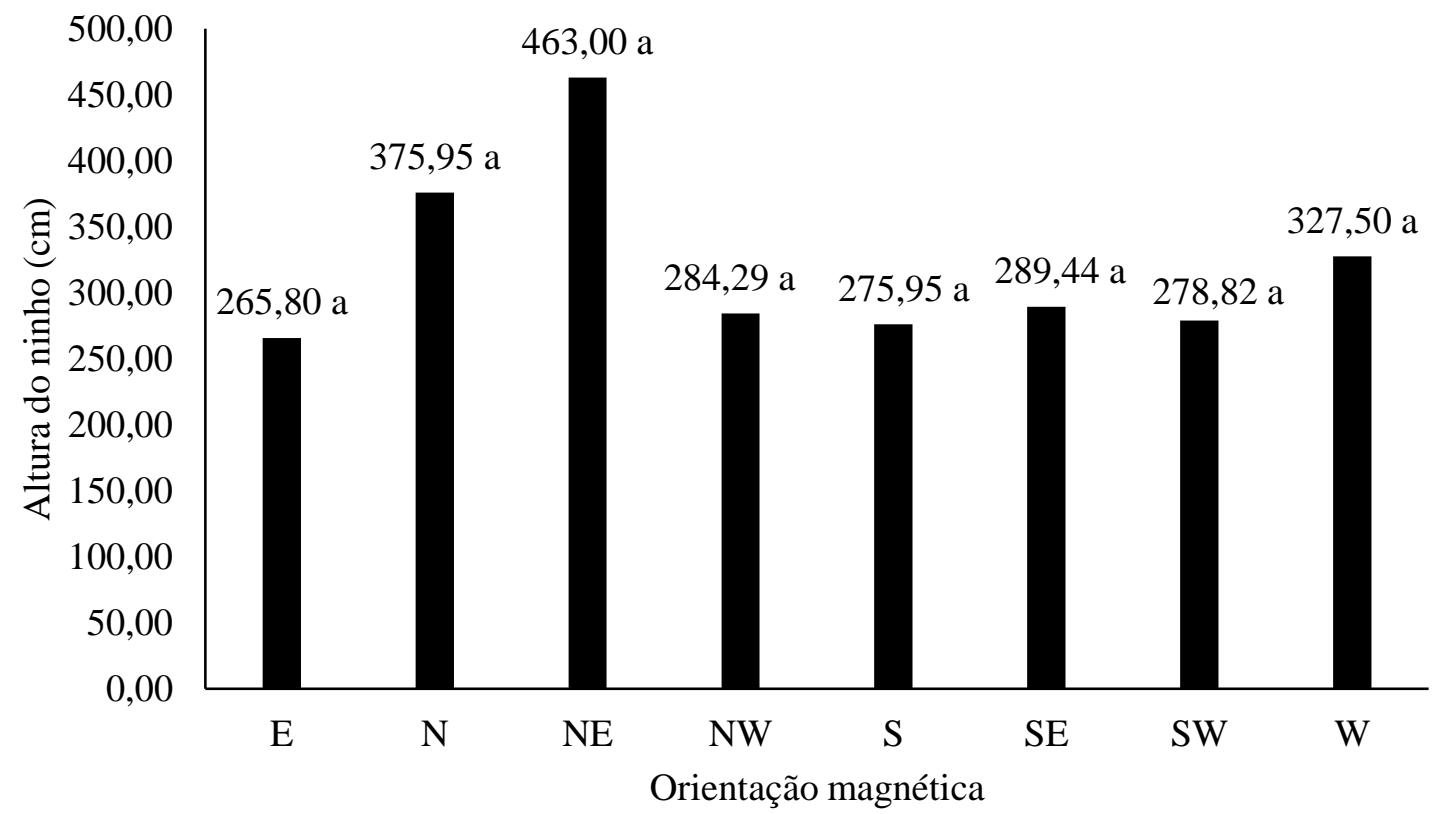

Fonte: Autores (2021).

Para Marchi (2008), em seu estudo sobre a nidificação de abelhas solitárias em área de Mata Atlântica, abelhas jovens podem se confundir, temporariamente, com a entrada do alvado por ocasião dos primeiros voos, demonstrando, eventualmente, aprendizado de localização e reconhecimento de seus ninhos.

Avaliando a influência da localização em relação ao diâmetro do alvado (Figura 12), diâmetro do tronco (Figura 13) e altura do ninho (Figura 14) na microrregião do Seridó Oriental Paraibano, verifica-se que não houve diferença significativa, ou seja, para os vários pontos dentro da microrregião do Seridó Oriental paraibano a nidificação de Xylocopa spp não diverge significativamente. Viana et al. (2002), por exemplo, identificaram que a alta regularidade de nidificações em Agaristha revoluta estava relacionada à grande disponibilidade deste hospedeiro vegetal na área estudada, além de apresentar maior diâmetro dos galhos em relação a outras espécies vegetais mais comuns.

Apesar de não diferir significativamente, verifica-se (Figura 12) que os maiores diâmetros de alvado foram encontrados no Sítio Viração (SV) e Sítio Novo Horizonte (SNH), ficando o Sítio Novo Horizonte (SODO) com os menores valores. 
Figura 12. Influência do local de estudo (SNH: Sítio Novo Horizonte; SODO: Sítio Olho D’água das Onças SV: Sítio Viração) na nidificação de abelhas Xylocopa spp em relação ao diâmetro do alvado. Médias com letras iguais não diferem estatisticamente pelo teste de Tukey $(\mathrm{p} \leq 0,05)$.

[

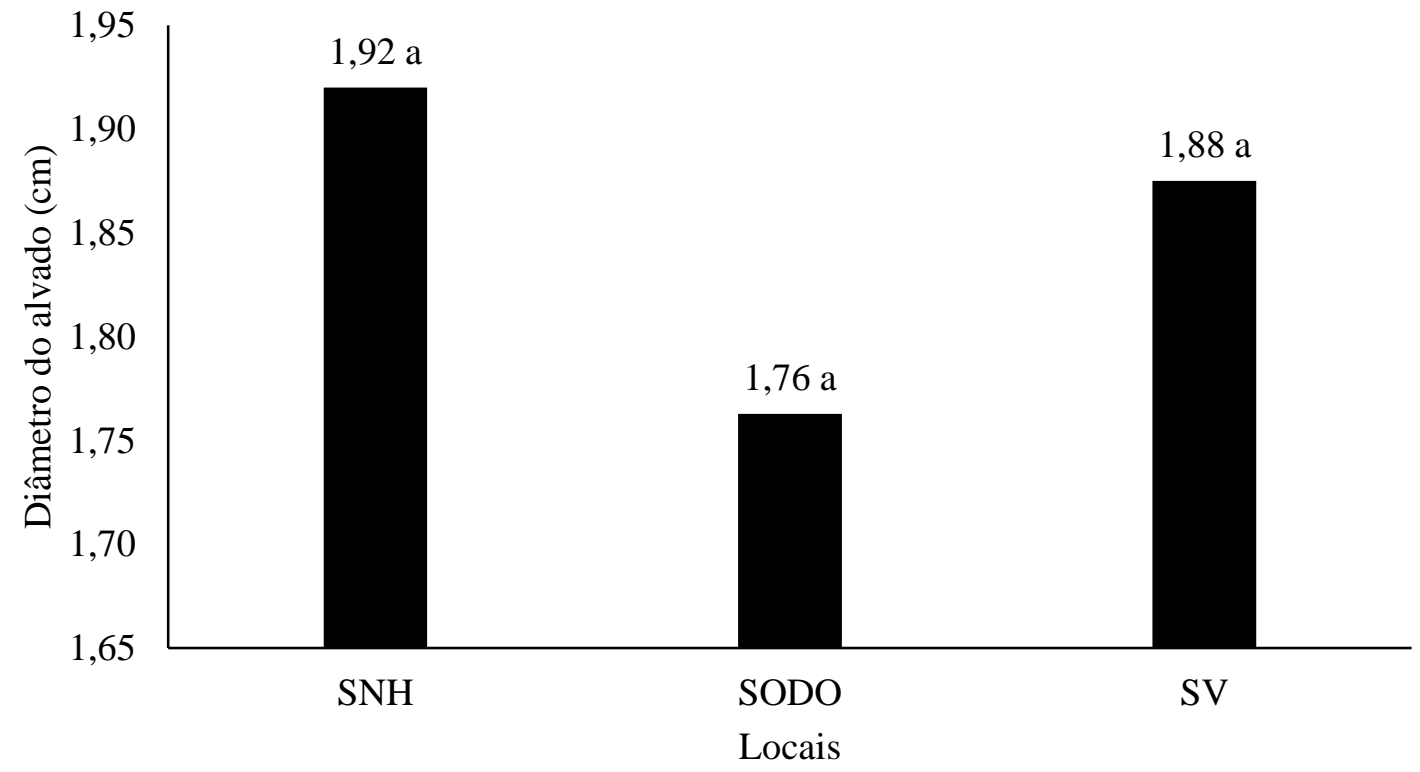

Fonte: Autores (2021).

Pode-se deduzir que o diâmetro do alvado, escavado pelas abelhas está diretamente relacionado ao tamanho e características inerentes a espécie da abelha nidificante.

Em relação ao diâmetro do tronco (Figura 13), o Sítio Viração (SV) apresentou a maior medida onde o menor diâmetro foi encontrado no Sítio Novo Horizonte (SNH). O SV, é a área entre as três que, apresenta remanescente de vegetação nativa, fator este que justifica a existência de substratos vegetais com maiores diâmetros e consequentemente maior longevidade. De acordo com Benevides et al. (2009), comunidades de polinizadores são influenciadas por diferentes pressões antrópicas e as consequências da fragmentação florestal. 
Figura 13. Influência do local de estudo (SNH: Sítio Novo Horizonte; SODO: Sítio Olho D’água das Onças SV: Sítio Viração) na nidificação de abelhas Xylocopa spp em relação ao diâmetro do tronco. Médias com letras iguais não diferem estatisticamente pelo teste de Tukey $(\mathrm{p} \leq 0,05)$.

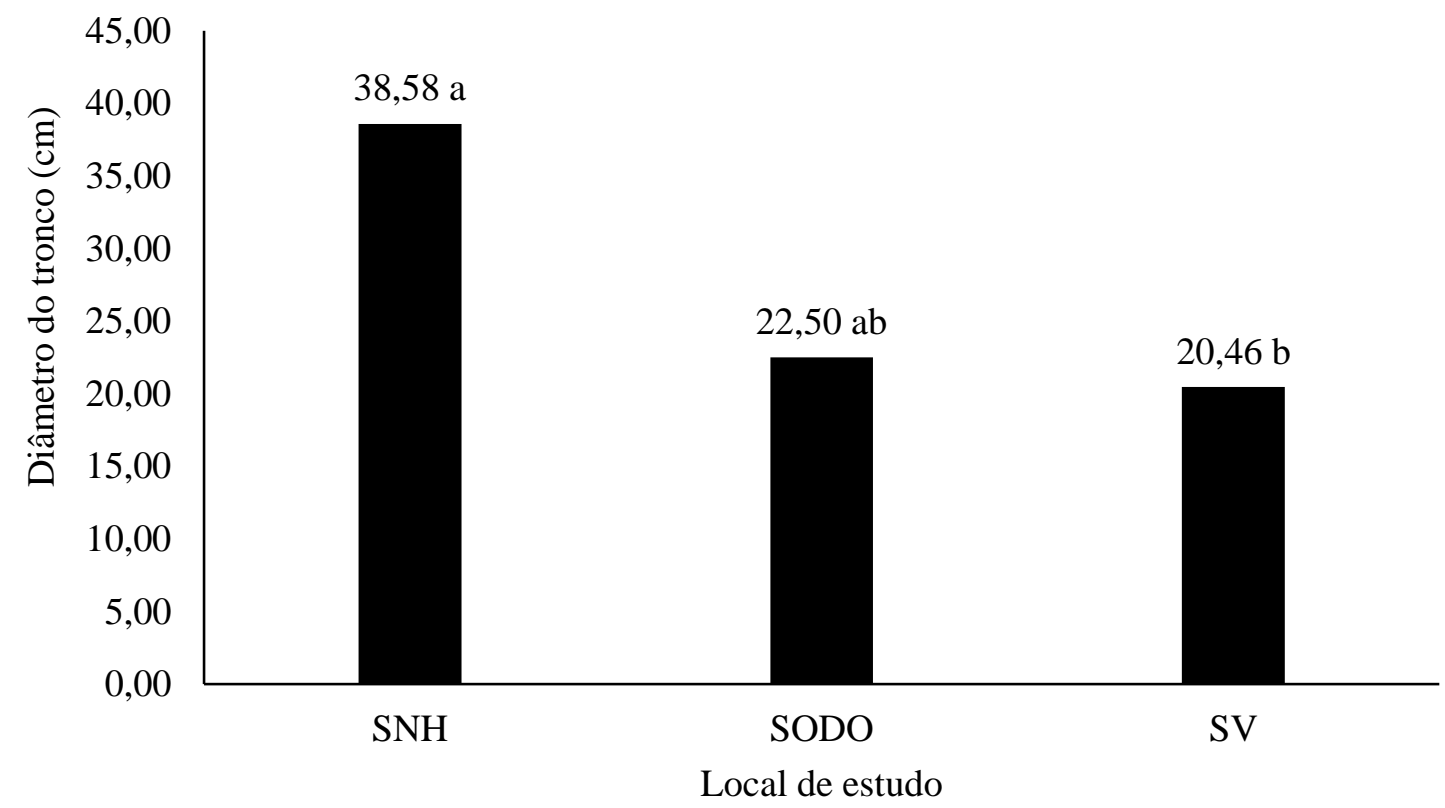

Fonte: Autores (2021).

No caso da altura do ninho em relação ao local de estudo (Figura 14), o Sítio Viração (SV) apresentou as maiores alturas de nidificação; o Sítio Olho D'água das Onças (SODO), as menores. Outro fator também diretamente relacionado ao grau de preservação da área, uma vez que a presença de remanescente de vegetação nativa na área disponibiliza espécies vegetais de porte alto, podendo ultrapassar o limite de altura observado para nidificação de abelhas. 
Figura 14. Influência do local de estudo (SNH: Sítio Novo Horizonte; SODO: Sítio Olho D’água das Onças SV: Sítio Viração) na nidificação de abelhas Xylocopa spp em à altura do ninho. Médias com letras iguais não diferem estatisticamente pelo teste de Tukey $(\mathrm{p} \leq 0,05)$.

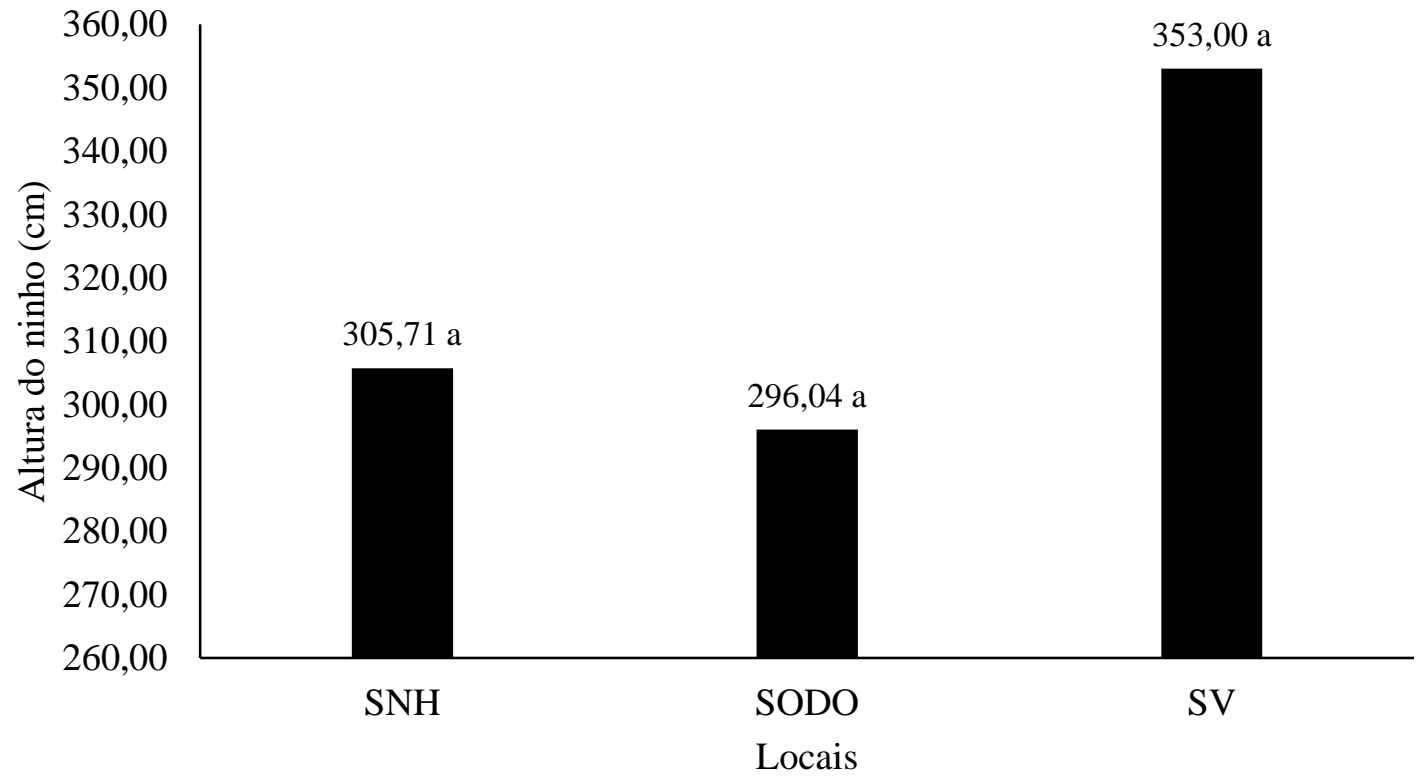

Fonte: Autores (2021).

Quanto à altura dos ninhos nas plantas, Siqueira et al. (2014) observaram um maior número em troncos com uma altura variável de $130 \mathrm{~cm}$ a $290 \mathrm{~cm}$ do solo. Viana et al. (2014), entretanto, verificaram uma maior periodicidade de ninhos de Xylocopa spp. em hospedeiros vegetais com altura entre 140 a $320 \mathrm{~cm}$ em relação ao solo.

\section{Conclusão}

As observações desse estudo permitem tirar as seguintes conclusões em relação a nidificação da abelha Xylocopa spp. no Seridó oriental da Paraíba:

1. Na microrregião do Seridó Oriental Paraibano, as abelhas Xylocopa spp. apresentam preferência de nidificação na direção voltada para o ponto colateral Sudoeste (SW);

2. Não há influência da orientação magnética em relação ao diâmetro do substrato, diâmetro do alvado e altura do ninho (em relação ao solo);

3. A prevalência de nidificação de Xylocopa spp. ocorre em quatro espécies vegetais: Annacardium occidentale, Commiphora leptophloeos, Erythrina mulungu e Tabebuia caraíba;

4. As espécies do gênero Xylocopa de maior ocorrência na microrregião do Seridó Oriental Paraibano são a Xylocopa (Neoxylocopa) grisescens Lepeletier, 1841 e a X. (Neoxylocopa) cearenses Ducke, 1910.

Estudos adicionais são necessários para se conhecer o hábito de nidificação do gênero Xylocopa em outras microrregiões. 


\section{Agradecimentos}

Aos proprietários dos sítios Olho D’água das Onças, Novo Horizonte e Viração (SV) por terem cedido suas propriedades para a condução dessa pesquisa.

\section{Referências}

Acosta-Avalos D., Esquivel, D. M., Wajnberg, E., Barros, H. G., Oliveira, P. S. \& Leal, I. (2001). Seasonal patterns in the orientation system of the migratory ant Pachycondyla marginata, Naturwissenschaften, 88(8): 343-6. https://doi.org/10.1007/s001140100245.

Almeida, F. A. V. (2016). Recursos usados por abelhas do gênero Xylocopa (Himenoptera, Apidae) e seu manejo em cultivo agrícola. 57 f. Dissertação (Mestrado) - Curso de Zootecnia, Universidade Federal do Ceará, Fortaleza.

Anzenberger, G. (1986). How do carpenter bees recognize the entrance of their nests? Ethology, 71(1): 54-62. DOI:10.1111/j.1439-0310.1986.tb00569.x.

Benevides, C. R., Gaglianone, M. C. \& Hoffmann, M. (2009). Visitantes florais do maracujá-amarelo (Passiflora edulis f. flavicarpa Deg. Passifloraceae) em áreas de cultivo com diferentes proximidades a fragmentos florestais na região Norte Fluminense, RJ. Revista Brasileira de Entomologia, 53(3): 415-421. https://doi.org/10.1590/S0085-56262009000300016.

Bernardino, A. S. (2008). Biologia de nidificação e estratégias de manejo de Xylocopa ordinaria e Xylocopa frontalis (Hymenoptera: Apidae) no norte do Rio de Janeiro. 100 f. Dissertação (Mestrado em Ecologia e Recursos Naturais) - Universidade Estadual do Norte Fluminense Darcy Ribeiro. http://www.uenf.br/Uenf/Downloads/pgecologia_5718_1218466564.pdf

Camillo, E., Garófallo, C. A. (1982). On the bionomics of Xylocopa frontalis (Olivier) and Xylocopa grisensces (Lepeletier) in southern Brazil. I. Nest construction and biological cycle. Revista Brasileira de Biologia 42: 571-582.

Chaves-Alves, T. M. (2009). Nidificação de Xylocopa spp. (Apidae, Xylocopini) em ninhos-armadilha em áreas de cerrado do Triângulo Mineiro. 60 f. Dissertação (Mestrado em Ecologia e Conservação de Recursos Naturais) - Universidade Federal de Uberlândia.

Chaves-Alves, T. M., Junqueira, C. N., Rabelo, L. S., Oliveira, P. E. A. M \& Augusto, S. C. (2011). Recursos ecológicos utilizados por las especies de Xylocopa (Hymenoptera, Apidae) en el área urbana. Revista Colombiana de Entomologia, 37(2): 313 -317.

Freitas, B. M. \& Oliveira Filho, J. H. (2001). Criação racional de mamangavas: para polinização em áreas agrícolas. Fortaleza: Banco do Nordeste, 96 p. il.

Gerling, D., Velthuis, H. H. W. \& Hefetz, A. (1989). Bionomics of the large carpenter bees of the genus Xylocopa. Annual Review of Entomology, 34: 163-190.

Hefetz, A. (1992). Individual scent marking of the nest entrance as a mechanism for nest recognition in Xylocopa pubescens (Hymenoptera: Anthophoridae). Journal of Insect Behavior, 5(6): 763-772. https://doi.org/10.1007/BF01047985.

Junqueira, C. N. (2016). Serviços de polinização e manejo de polinizadores do maracujá-amarelo (Passiflora edulis f. flavicarpa Deneger). 136 f. Tese (Doutorado) - Curso de Ecologia e Conservação de Recursos Naturais, Programa de Pós-Graduação em Ecologia e Conservação de Recursos Naturais, Universidade Federal de Uberlândia, Uberlândia - MG. http://repositorio.ufu.br/bitstream/123456789/18313/1/ServicosPolinizacaoManejo.pdf

Lacerda, D. C. O. (2016). Influência da orientação magnética na nidificação de abelhas nativas na zona da mata pernambucana. 73 f. Dissertação (Mestrado) - Curso de Programa de Pós-Graduação em Ciências Agrárias (Agroecologia), Centro de Ciências Humanas, Sociais e Agrárias, Universidade Federal da Paraíba, Bananeiras-PB.

Macêdo, C. R. C. (2017). Comportamento da nidificação de abelhas melíponas no curimataú paraibano. 144 f. Dissertação (Mestrado) - Curso de Programa de Pós Graduação em Ciências Agrárias (Agroecologia), Centro de Ciências Humanas, Sociais e Agrárias, Universidade Federal da Paraíba, Bananeiras-PB.

Macêdo, C. R. C., Aquino, I. S., Borges, P. F., Barbosa, A. S. \& Medeiros, G. R. (2020). Nesting behavior of stingless bees. Ciência Animal Brasileira, 21: e58736-e-58736. 10.1590/1809-6891v21e-58736

Marchi, P. (2008). Biologia da nidificação de abelhas solitária em áreas de mata atlântica. Curitiba. Tese (Doutorado em Entomologia) - Universidade Federal do Paraná, 87 p.

Marchi, P. \& Melo, G. A. R. (2010). Biologia de nidificação de Xylocopa (Neoxylocopa) frontalis (Olivier) (Hymenoptera, Apidae, Xylocopini) em Morretes, Paraná. Oecologia Australis, v. 14, n. 1, p. 210-231. DOI:10.4257/oeco.2010.1401.12

Marchi, P. \& Santos, I. A. (2013). As abelhas do gênero Xylocopa Latreille (Xylocopini, Apidae) do Estado de São Paulo, Brasil. Biota Neotropica, 13(2): 249269. https://doi.org/10.1590/S1676-06032013000200025

Martins, C. F., Ferreira, R. P. \& Carneiro, L. T. (2012). Influence of the Orientation of Nest Entrance, Shading, and Substrate on Sampling Trap-Nesting Bees and Wasps. Neotropical Entomology, 41(2):105-11. 10.1007 / s13744-012-0020-5

Oliveira Filho, J. H. \& Freitas, B. M. (2003). Colonização e biologia reprodutiva de Xylocopa frontalis em um modelo de ninho racional. Ciência Rural, 33(4): 693-697. https://doi.org/10.1590/S0103-84782003000400017

Oliveira, P. E., Augusto, S. C., Barbosa, A. A. A., Yamamoto, M., Silva, J. R. (2014). Polinização e produção do maracujá-amarelo (Passiflora edulis f. flavicarpa) no Triângulo Mineiro e possibilidades de manejo sustentável de Xylocopa spp. (Apidae, Xylocopini). In: Yamamoto, M, Oliveira, P. G. \& Gaglianone, M. C. Uso sustentável e restauração da diversidade dos polinizadores autóctones na agricultura e nos ecossistemas relacionados: planos de manejo. Rio de Janeiro, Funbio, 404 p. 
Pereira, M. \& Garófalo, C. A. (2010). Biologia da nidificação de Xylocopa frontalis e Xylocopa grisescens (Hymenoptera, Apidae, Xylocopini) em ninhosarmadilha. Oecologia Australis, 14(1): 193-209. DOI:10.4257/oeco.2010.1401.11

Santos, M. R. \& Costa-Neto, E. M. (2012). O mangangá (Xylocopa spp., Apidae) como polinizador do maracujá-amarelo (Passiflora edulis sims f. flavicarpa Deneger, Passifloraceae) na percepção dos moradores de Gameleira do Dida, campo formoso, Bahia, Brasil. Aracaju: Interfaces Científicas - Saúde e Ambiente, 1(1): 19-29. https://doi.org/10.17564/2316-3798.2012v1n1p19-29

Santos, R. M. S. (2016). Contribuição à elaboração de um guia das abelhas nativas do Brasil. 222 f. Dissertação (Mestrado) - Curso de Programa de Pósgraduação em Sistemas Agroindustriais, Centro de Ciências e Tecnologia Agroalimentar, Universidade Federal de Campina Grande, Pombal-PB. http://150.165.111.246/ojs-pombal/index.php/PPSA/article/viewFile/139/89

Silva, F. J. A., Aquino, I. S., Barbosa, A. S. \& Borges, P. F. (2021). Comportamento de nidificação de Melipona scutellaris (Latreille, 1811). Research, Society and Development, 10(7):1-15. https://doi.org/10.33448/rsd-v10i7.16350

Siqueira, K. M. M., Kiill, L. H. P. \& Araújo, F. P. (2014). Proposta de manejo de polinizadores em espécies de Passifloraceae no Vale do Submédio do São Francisco. p. 345-367. In: Yamamoto, M.; Oliveira, P.G. \& Gaglianone, M.C. Uso sustentável e restauração da diversidade dos polinizadores autóctones na agricultura e nos ecossistemas relacionados: planos de manejo. Rio de Janeiro, Funbio, 404 p.

Schlindwein, C., Schlumpberger, B., Wittmann, D. \& Moure, J. S. (2003). O gênero Xylocopa Latreille no Rio Grande do Sul, Brasil (Hymenoptera, Anthophoridae). Revista Brasileira de Entomologia, 47(1): 107-118. https://doi.org/10.1590/S0085-56262003000100016

Vaz, M. A. (2015). Influência dos pontos cardeais e colaterais na nidificação de abelhas nativas. 30 f. Dissertação (Mestrado) - Curso de Programa de Pós Graduação em Ciências Agrárias (Agroecologia), Centro de Ciências Humanas, Sociais e Agrárias, Universidade Federal da Paraíba, Bananeiras-PB.

Viana, B. F, Kleinert, A. M. P. \& Silva, F. O. (2002). Ecologia de Xylocopa (Neoxylocopa) cearensis (Hymenoptera, Anthophoridae) nas dunas litorâneas de Abaeté, Salvador, Bahia. Iheringia. Série Zoologia, 92(4): 47-57. 10.1590/S0073-47212002000400007

Viana, B. F., Silva, D. E., Almeida, A. A. (2014). Polinização do maracujá-amarelo no semiárido da Bahia. p. 255-280. In: Yamamoto, M.; Oliveira, P.G. \& Gaglianone, M.C. Uso sustentável e restauração da diversidade dos polinizadores autóctones na agricultura e nos ecossistemas relacionados: planos de manejo. Rio de Janeiro, Funbio, 404 p. 